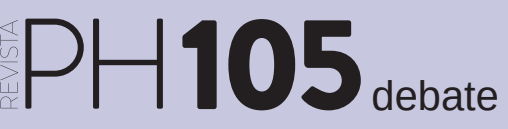

Interpretación y gestión del patrimonio en los espacios del turismo oscuro

coordinan Óscar Navajas Corral y Maribel Rodríguez Achútegui

\title{
Memoria, trauma y experiencia. Sobre los patrimonios conflictivos y el turismo oscuro
}

Carmen Ortiz García | Instituto de Historia, Consejo Superior de Investigaciones Científicas

URL de la contribución <www.iaph.es/revistaph/index.php/revistaph/article/view/5028>

La que podríamos calificar como obsesión de nuestras sociedades con la memoria -la memoria social, más aún que la memoria individual- se ha relacionado con ciertos elementos que caracterizan nuestro mundo actual y que, paradójicamente, no se compaginan bien con la memoria, como, por ejemplo, la rapidez de los cambios, la fluidez de las situaciones y la pérdida de las normas nemotécnicas y las formas narrativas que sirven de anclaje a la memoria personal y comunitaria.

La crisis de la historia y la supuesta objetividad de su relato se ha puesto, asimismo, en confrontación con el carácter eminentemente moral y auténtico de la memoria y la experiencia de los propios actores, sujetos del pasado histórico. La urgencia de recurrir a ese pasado -un lugar extraño, no lo olvidemos, como ya explicó David Lowenthal (1989)- tiene que ver con el presente y la utilidad del pasado para legitimar sistemas que compiten en la arena política, y para conseguir unos rasgos de identidad entre los ciudadanos acordes con formas de gobierno, de Estados o de dominio que se pretenden establecer basándose en la naturalización de esos rasgos distintivos. La memoria social, como experiencia recreada y compartida, es así un terreno para elaborar representaciones patrimoniales simbólicas del pasado, y donde es necesario construir materialmente lugares, paisajes, objetos, que anclen el recuerdo y sancionen el olvido (Huyssen 2003).

Si los historiadores hace ya tiempo que siguen el mandato que dejó escrito Walter Benjamin (1989) acerca de la necesidad de ver la historia humana -o la occidental, si queremos- como un proceso en el que la barbarie, la destrucción y la guerra están permanente y esencialmente presentes, en el análisis de la construcción social del patrimonio esta realidad no podía dejar de estar presente. Hay memoria de estos traumas en el presente y, en consecuencia, ha emergido un patrimonio al que se han puesto distintos adjetivos para definirlo: traumático, incómodo, indeseado, conflictivo, doloroso, discutido, negativo, etc. Los ejemplos de esta clase de museos, lugares de memoria, paisajes y sitios musealizados no han hecho más que crecer desde el comienzo del siglo (Tunbridge y Ashworth 1996; Meskell 2002; Logan y Reeves 2009).

La relación de este tipo de patrimonio con hechos catastróficos, genocidios, matanzas, guerras, cárceles, etc. conlleva que, tanto simbólica como materialmente, sea conflictivo; que separe, de manera más o menos irreconciliable, al menos dos memorias: la de los perpetradores y la de las víctimas, y que esté cargado de elementos morales y sociales enfrentados en su valoración. Las funciones que puedan corresponder a este patrimonio son también específicas y sobrepasan las habituales esgrimidas por los técnicos para justificar su conservación: la educación, la enseñanza histórica, o la creación de conciencia ciudadana en torno a bienes como la paz, la democracia, la justicia, etc. El reconocimiento de esta herencia patrimonial de hechos que es doloroso rememorar es más difícil de aceptar que el de bienes que remiten a hechos cargados con valores positivos, y por lo tanto, a veces, es discutida la necesidad de mantener su memoria. El reconocimiento de culpa, el recuerdo del dolor causado, la destrucción inconmensurable que muchos de estos patrimonios representan requieren de un tratamiento, una representación y, en suma, una gestión distinta que va más allá de la propia patrimonialización (Roigé 2016); incluso esta puede ser discutida por los mismos sujetos objeto de los actos o discursos patrimoniales. 
En función de estas características distintivas, los patrimonios conflictivos, a mi juicio, no deben relacionarse de un modo orgánico con el llamado "turismo oscuro" que, en un momento determinado, o en casos concretos de lugares patrimoniales relacionados con el dolor, la muerte, la tortura o el encarcelamiento, puede constituirse legítimamente como un visitante o consumidor masivo. Muchas veces el patrimonio dirigido al turismo se construye para un "otro" con el que se marcan explícitas diferencias. El patrimonio que tiene que ver con las memorias traumáticas, sobre todo si está relacionado con procesos de justicia o reconciliación, se vuelca hacia un nosotros, enfocado como una comunidad simbólica, proyectada hacia el futuro

Hay un rasgo común en la búsqueda y la visita de lugares donde ocurrieron desgracias conocidas y recordadas. Se trata del carácter experiencial que la presencia en sitios donde se cometieron actos de violencia, explotación, tortura, privación de libertad, etc. proporciona por sí sola. La entrada a una cárcel, incluso sin el acompañamiento guiado de antiguos prisioneros o carceleros por sus estancias, por sí misma conlleva una gran comprensión del hecho del encarcelamiento y sus consecuencias en las personas. Esta experiencia de la abyección puede ser buscada por múltiples motivos y muy variadas personas. Sin embargo, la significación de su memoria no puede ser la misma para aquellos que, de alguna manera más o menos directa, sufrieron el encarcelamiento. Esta experiencia se puede transmitir de varias maneras, pero no sustituirse de forma banal. De hecho, gran parte del atractivo que estas ruinas del mal representan para mucha gente radica precisamente en su contacto material, encarnado, real, con determinadas personas individuales y concretas. No solo se está ante la huella de un preso anónimo, un judío abstracto, un disidente político cualquiera, sino de uno de nosotros; uno como nosotros, del cual portamos la memoria que compartimos.

Por este motivo, a mi juicio, el carácter de banalización, de mercantilización, de masividad impersonal que la práctica del turismo oscuro, y sus motivaciones distintas, conlleva no debe confundirse con el fundamento, que se

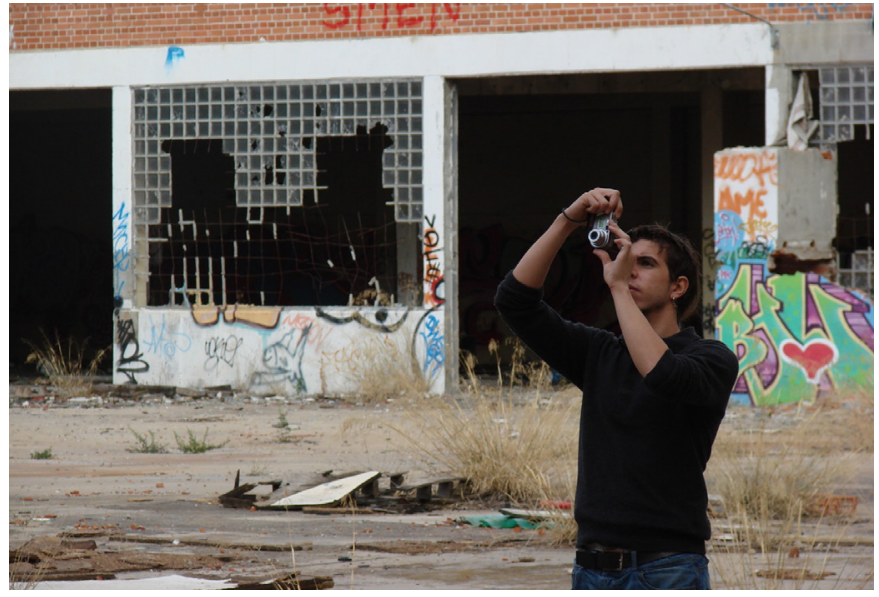

Visitas a las ruinas de la cárcel de Carabanchel, 27 de septiembre de 2008

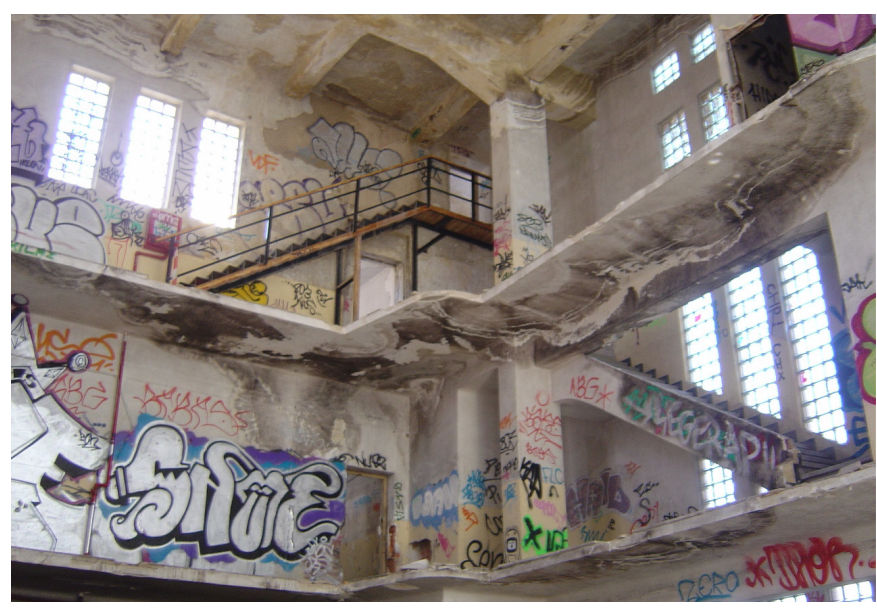

Estructura de acceso a los pisos de las galerías de la cárcel, noviembre 2007 | fotos Víctor Fernández

ha querido ver como sagrado en algunos casos, como el Holocausto y los campos de exterminio (Young 1993), que tienen los patrimonios traumáticos. Hace poco, este asunto fue tratado en un artículo por el escritor Manuel Vicent (El País, 23-10-2021, p. 29). Coincido con él en el sentido profundo que pueden tener algunos lugares y la banalización consumista que también llevan aparejada:

"Mi visita al campo de concentración de Mauthausen coincidió con la excursión de un colegio cuyos alumnos adolescentes rubios y fuertes entraron en tropel bromeando en la cámara de gas. Ni siquiera allí dentro 
a debate Interpretación y gestión del patrimonio en los espacios del turismo oscuro

| coordinan Óscar Navajas Corral y Maribel Rodríguez Achútegui

cesaron sus risas [...] Fuera de la cámara de gas, ante una pared cubierta de fotografías un anciano solitario lloraba de rodillas....".

En el mismo texto rememora las celdas de la cárcel de Carabanchel en que se producían los encuentros íntimos, llamados vis a vis, entre los internos y sus parejas... La visión de la cama y de la celda convoca en tropel toda una serie de recuerdos, sensaciones, momentos, olores, palabras, ruidos, difíciles de representar.

Podría aducirse que en cualquier museo de arte, en la contemplación de cualquier obra humana, encontraríamos las mismas actitudes extremas y diversas... Y, por lo tanto, no habría ninguna diferencia en cuanto al tipo de patrimonio. Pero no es lo mismo... no es lo mismo una cosa que otra.

\section{BIBLIOGRAFÍA}

- Benjamin, W. (1989) Tesis de Filosofía de la historia. Discursos interrumpidos I. Filosofía del Arte y de la Historia. Madrid: Taurus, pp. 179-191

- Huyssen, A. (2003) Present Pasts. Urban Palimpsests and the Politics of Memory. Stanford: Stanford University Press

- Logan, W. y Reeves, K. (2009) Places of Pain and Shame: Dealing with Difficult Heritage. Londres: Routledge

- Lowenthal, D. (1998) El pasado es un país extraño. Madrid: Akal

- Meskell, L. (2002) Negative Heritage and past mastering in Archaeology. Anthropological Quarterly, vol. 75, n. ${ }^{\circ} 3$, pp. 557574

- Roigé, X. (2016) De monumentos de piedra a patrimonio inmaterial. Estrategias políticas, museológicas y museográficas de presentación de la memoria. En: Arrieta, I. (ed.) Lugares de memoria traumática. Representaciones museográficas de conflictos políticos armados. Bilbao: Universidad del País Vasco, pp. 23-47

- Tunbridge, J.E. y Ashworth, G.J. (1996) Dissonant Heritage: the management of the past as a resource in conflicto. Chichester, N. York: J. Wiley

- Young, J. E. (1993) The Texture of Memory. Holocaust, Memorials and Meaning. New Haven y Londres: Yale University Press 